\title{
Ion production rate in a boreal forest based on ion, particle and radiation measurements
}

\author{
L. Laakso ${ }^{1}$, T. Petäjä ${ }^{1}$, K. E. J. Lehtinen ${ }^{1}$, M. Kulmala ${ }^{1}$, J. Paatero ${ }^{2}$, U. Hõrrak ${ }^{3}$, H. Tammet ${ }^{3}$, and J. Joutsensaari ${ }^{4}$ \\ ${ }^{1}$ Department of Physical Sciences, P.O. Box 64, FI-00014 University of Helsinki, Finland \\ ${ }^{2}$ Finnish Meteorological Institute, Air Quality Research, Sahaajankatu 20E, FIN-00880 Helsinki, Finland \\ ${ }^{3}$ Institute of Environmental Physics, University of Tartu, 18 Ülikooli Street, Tartu, 50090, Estonia \\ ${ }^{4}$ Department of Applied Physics, University of Kuopio, P.O. Box 1627, FIN-70211 Kuopio, Finland
}

Received: 23 April 2004 - Published in Atmos. Chem. Phys. Discuss.: 20 July 2004

Revised: 17 September 2004 - Accepted: 21 September 2004 - Published: 29 September 2004

\begin{abstract}
In this study the ion production rates in a boreal forest were studied based on two different methods: 1) cluster ion and particle concentration measurements, 2) external radiation and radon concentration measurements. Both methods produced reasonable estimates for ion production rates. The average ion production rate calculated from aerosol particle size distribution and air ion mobility distribution measurements was 2.6 ion pairs $\mathrm{cm}^{-3} \mathrm{~s}^{-1}$, and based on external radiation and radon measurements, 4.5 ion pairs $\mathrm{cm}^{-3} \mathrm{~s}^{-1}$. The first method based on ion and particle measurements gave lower values for the ion production rates especially during the day. A possible reason for this is that particle measurements started only from $3 \mathrm{~nm}$, so the sink of small ions during the nucleation events was underestimated. It may also be possible that the hygroscopic growth factors of aerosol particles were underestimated. Another reason for the discrepancy is the nucleation mechanism itself. If the ions are somehow present in the nucleation process, there could have been an additional ion sink during the nucleation days.
\end{abstract}

\section{Introduction}

Nucleation followed by particle growth has recently been observed at various locations and by several research groups (see overview by Kulmala et al. (2004) and references therein). Although these bursts of new particles have been frequently observed, the mechanisms of particle formation still remain unclear. Several nucleation mechanisms have been proposed, including classical binary homogeneous nucleation, ternary nucleation (Kulmala et al., 2000a), ioninduced nucleation and ion-mediated nucleation ( $\mathrm{Yu}$ and

Correspondence to: L. Laakso

(lauri.laakso@iki.fi)
Turco, 2000). Recent results indicate the possibility of barrierless nucleation (Laakso et al., 2004). None of the mechanisms have been confirmed or rejected yet and it may be possible, that several of these mechanisms are simultaneously effective in the atmosphere.

For ion-induced nucleation, the ion production rate is one of the factors governing the nucleation rates. Even if condensation is enhanced by electric interactions (Yu and Turco, 2000), the maximum nucleation rate is still equal to the ion production rate. This is one of the reasons why the ion production rate is such a key quantity in atmospheric physics. The measurements of the ionization rate can be divided into two groups: direct measurements by means of ionization chambers and indirect measurements based on calculations according to the balance equation for small air ions. If different measuring methods are compared, the measurement method, measuring height and time (summer/winter) should be given.

Overviews of the earlier measurements (mainly before 1950) of the ionization rate have been made by Israel (1970, 1973) and Chalmers (1967). An average ionization rate of 10 ion pairs $\mathrm{cm}^{-3} \mathrm{~s}^{-1}$ is considered a standard at the height of $1 \mathrm{~m}$ from the ground in continental areas.

Considering different locations, the ionization rate could exhibit considerable variation depending on the content of radioactive substances in the ground, on the soil properties, on the water content of the snow cover, and due to local orography. The measurements below $1 \mathrm{~m}$ strongly depend on the ionization profile. The ionization rate decreases with altitude near the ground up to about $1-2 \mathrm{~km}$, and increases with altitude with a maximum of about 50 ion pairs $\mathrm{cm}^{-3} \mathrm{~s}^{-1}$ near 15 km (Hoppel et al., 1986; Mohnen, 1977; Rosen et al., 1985).

In continental areas, the temporal variation of the ionization rate (annual and diurnal variation) is mostly due to the variation in radon and thoron concentration. The ionization 
rate can be used as an indicator of boundary layer stability similarly as the concentration of radon (Porstendörfer, 1994; Kataoka et al., 1998).

Galactic cosmic rays (GCR) are the primary ionization source above the oceans. The intensity of the cosmic rays in the atmosphere is modulated by the 11-year solar cycle. This modulation increases as a function of height (Larsen, 1993). A comprehensive review of ionization rate measurements in marine environments was compiled by Hensen and van der Hage (1994), depicting a variation in ionization rate from 1.5 to $2.9 \mathrm{~cm}^{-3} \mathrm{~s}^{-1}$ within different latitudes.

Ionization rates have recently been measured by (Dhanorkar and Kamra, 1994; Wilkening, 1985; Mochizuki et al., 1977; Hensen and van der Hage, 1994). Dhanorkar and Kamra (1994) have used a set of integral ion counters to measure the small ion concentration and the aerosol ion mobility distribution at a height of about $1 \mathrm{~m}$ above the ground at Pune, India. The ionization rate was calculated based on a balance equation. The two-day measurements showed a diurnal variation of the ionization rate with a minimum of 2.75 ion pairs $\mathrm{cm}^{-3} \mathrm{~s}^{-1}$ at noon and a maximum of 117 ion pairs $\mathrm{cm}^{-3} \mathrm{~s}^{-1}$ in the early morning.

Wilkening (1985) measured small ion and radon concentrations in Carlsbad Caverns in southwestern United States. The ion pair production rates have been estimated from a knowledge of the radon $\left({ }^{220} \mathrm{Rn},{ }^{222} \mathrm{Rn}\right)$ concentrations, and their daughters under equilibrium conditions in outdoor air, and from published values of cosmic ray fluxes. The estimated ion production rates for the Langmuir Laboratory for Atmospheric Researh $(3240 \mathrm{~m} \mathrm{msl})$ and for Rio Grande Valley at Socorro $(1410 \mathrm{~m})$ were 10 and 15 ion pairs $\mathrm{cm}^{-3} \mathrm{~s}^{-1}$, respectively. The estimate for Carlsbad Caverns (230 m underground, surface elevation $1340 \mathrm{~m}$ ) was 2300 ion pairs $\mathrm{cm}^{-3} \mathrm{~s}^{-1}$.

Mochizuki et al. (1977) designed an ionization chamber for continuous monitoring of the ion formation rate in the atmosphere. Results for one day at two different levels $(0.2 \mathrm{~m}$ and $1 \mathrm{~m}$ ) were presented. The diurnal variation of the ionization rate at $1 \mathrm{~m}$ has a minimum of 6 ion pairs $\mathrm{cm}^{-3} \mathrm{~s}^{-1}$ at noon and a maximum of 13 ion pairs $\mathrm{cm}^{-3} \mathrm{~s}^{-1}$ during nighttime. The ionization rate at a height of $0.2 \mathrm{~m}$ displayed the same pattern, but was about two times higher (minimum 10 ion pairs $\mathrm{cm}^{-3} \mathrm{~s}^{-1}$ and maximum 22 ion pairs $\mathrm{cm}^{-3} \mathrm{~s}^{-1}$ ). This can be attributed to the steep radon concentration gradient in the air close to the ground (Liu et al., 1984).

Since the ion production rate is such a crucial factor when investigating the charging state of aerosols and the possibility of ion-induced nucleation, it is studied in further detail, in this case in a Finnish boreal forest. Two independent methods for obtaining the ion production rate are compared. The first method is based on a balance equation for small cluster ions and the second method on the measurements of radon and external radiation. The experiments were carried out during the QUEST (Quantification of aerosol nucleation in the European boundary layer) 2-measurement campaign in spring 2003 at SMEAR (Station for MEasuring forest ecosystem-Atmosphere Relations) II-measurement station $\left(61^{\circ} 51^{\prime} \mathrm{N}, 24^{\circ} 17^{\prime} \mathrm{E}, 180 \mathrm{~m}\right.$ above sea level) (Vesala et al., 1998; Kulmala et al., 2001) in Hyytälä, Finland.

\section{Experimental setup and theory}

In this study several different instruments were utilized. The mobility distribution of the ions was measured with a Balanced Scanning Mobility Analyzer (BSMA), of the particles with two differential mobility particle sizers (DMPS) and an aerodynamical particle sizer (APS). The ionizing radiation was measured by glass-fibre filters and a scintillation gamma spectrometer. All instruments are explained in more detail in the next sections.

\subsection{BSMA}

The Balanced Scanning Mobility Analyzer (BSMS), manufactured by Airel Ltd., Estonia, consists of two plain aspiration-type differential mobility analyzers, one for positive and the other for negative ions. The two aspiration condensers are connected as a balanced bridge circuit that allows continuous variation of the driving voltage and scanning of the mobility distribution of charged clusters and nanoparticles, usually called air ions. A large airflow rate of 44 liters per second helps to suppress the loss of air ions in the inlet of the instrument. The inlet can be closed or opened for ions using a controlled electrostatic filter and the background signal is eliminated making every second scan with a closed inlet. A mobility distribution is calculated according to the results of 9 scans performed during $3 \mathrm{~min}$. The electrical mobility range of $0.032-3.2 \mathrm{~cm}^{2} \mathrm{~V}^{-1} \mathrm{~s}^{-1}$ is logarithmically uniformly divided into 16 fractions. The mobility distribution is converted to size distribution using the algorithm developed by Tammet (1995). The size distribution is presented by 12 fractions, logarithmically uniformly distributed in the diameter range of $0.4-6.3 \mathrm{~nm}$. The sampling height was about $1.6 \mathrm{~m}$ above the ground.

\subsection{DMPS}

For sub-micron particle sizing the main instrument used was the differential mobility particle sizer (DMPS), operated $2 \mathrm{~m}$ above the ground and with a time resolution of $10 \mathrm{~min}$. The system consists of two parallel DMPS devices: one classifying the particles between 3 and $10 \mathrm{~nm}$ and the other between 10 and $500 \mathrm{~nm}$. Both devices use a Hauke-type differential mobility analyzer (DMA) (Winklmayr et al., 1991) and a closed loop sheath flow arrangement (Jokinen and Mäkelä, 1997). The first device consists of a $10.9 \mathrm{~cm}$ long DMA and a TSI model 3025 Condensation Particle Counter (CPC) and the second one of a $28 \mathrm{~cm}$ long DMA and a TSI model 3010 CPC. Before sizing the aerosol is neutralized with a $74 \mathrm{MBq}$ ( $2 \mathrm{mCi}$ ) Krypton- 85 beta source. 
The conventional DMPS measures particle size distributions at dry conditions with a RH typically below $10 \%$. In addition to the dry conditions, we have measured particle size distributions at higher relatively humidifies with a wetDMPS system. In the wet-DMPS, the aerosol particles are humidified with water vapor before the particle size measurement. The wet-DMPS system consists of a Gore-Tex type aerosol humidifier, a Hauke-type DMA (10.9 cm long), a sheath air humidifier unit and an ultrafine CPC (TSI 3025). The construction of the system (e.g. humidifiers) is based on the hygroscopic tandem DMA described in detail by Joutsensaari et al. (2001). The size distributions were measured every $10 \mathrm{~min}$ at RH of $90 \%$ for $3-70 \mathrm{~nm}$ particles. The sampling height was about $4 \mathrm{~m}$ above the ground.

In principle, the freshly formed nucleation mode particles can be observed earlier with the wet-DMPS compared to the dry-DMPS if they grow to detectable size during humidification, i.e. particles below $3 \mathrm{~nm}$ in diameter (detection limit of the dry DMPS) at dry conditions can be detected.

\subsection{APS}

For large particle sizing, an aerodynamical particle sizer (APS) (model TSI 3320) was used. The APS measures particle size distributions from $0.7 \mu \mathrm{m}$ to $20 \mu \mathrm{m}$ by determining the time-of flight of individual particles in an accelerating flow field (Peters and Leith, 2003). The particle size distributions measured with the APS were transformed to mobility equivalent diameter by dividing the aerodynamic diameter by the square root of the estimated particle density of $1.9 \mathrm{~g} \mathrm{~cm}^{-3}$. This density has been found to give a good agreement between DMPS and APS size distributions (Aalto et al., 2001) in Hyytiälä during previous campaigns.

\subsection{Measurements of ionizing radiation}

In the lower troposphere, ions are created mainly by cosmic radiation, radiation from the ground and decay of radon emitted from the ground. Both of these ion sources are continuously measured in Hyytiälä. The sampling inlet is ca. $6 \mathrm{~m}$ above the ground. Measurements of airborne radon-222 have been made since March 2000.

\subsubsection{Measurements of radon}

The ${ }^{222} \mathrm{Rn}$ content of the air is monitored continuously by counting the beta particle emissions of the particle-bound daughter nuclides ${ }^{214} \mathrm{~Pb}$ and ${ }^{214} \mathrm{Bi}$ collected onto glass-fibre filters (see Fig. 1). ${ }^{222} \mathrm{Rn}$, being a noble gas, cannot be collected with aerosol filters. The beta activity of the short-lived ${ }^{222} \mathrm{Rn}$ progeny is distinguished from the ${ }^{220} \mathrm{Rn}$ progeny and artificial radioactivity by their half-life differences (Paatero et al., 1998). The air flow is directed through one of two filters alternately for four-hour periods. The count rate of the Geiger-Mueller (GM) tube increases as beta-active aerosol particles accumulate onto the filter. After four hours the air

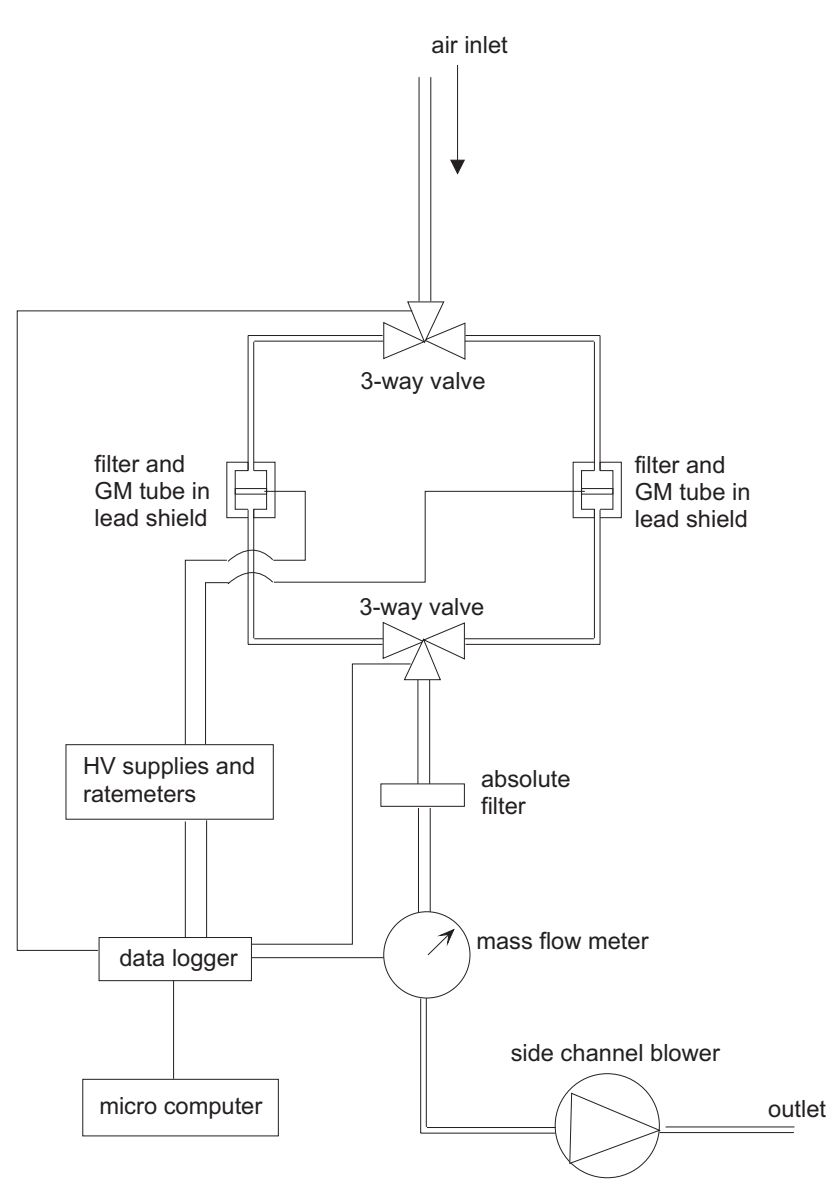

Fig. 1. Setup of the radon monitoring system (HV: high voltage, GM: Geiger-Mueller).

flow is directed through the other filter. If the beta activity on the first filter is due to ${ }^{222} \mathrm{Rn}$ progeny only, it decays practically completely during the following four hours and the count rate of the GM tube returns to base level. If, however, there is ${ }^{220} \mathrm{Rn}$ progeny or artificial radioactivity present on the filter, the count rate remains above the base line after the four-hour period due to the longer half-lives of these nuclides. ${ }^{222} \mathrm{Rn}$ was assumed to be in equilibrium with its shortlived progeny. The ion pair production rate caused by ${ }^{222} \mathrm{Rn}$ and its short-lived progeny was calculated by taking into consideration the total energy of the three alpha and the two beta particles and by assuming an average energy of $34 \mathrm{eV}$ per produced ion pair. The uncertainty of ionization rate caused by radon varies between $3 \%$ and $20 \%$ depending on the radon activity concentration.

\subsubsection{Measurements of external radiation}

External radiation consisting mainly of cosmic radiation and gamma radiation from the ground was measured with a scintillation gamma spectrometer system. A $76 \mathrm{~mm} \times 76 \mathrm{~mm}$ $\mathrm{NaI}(\mathrm{Tl})$ detector is placed in a shelter where a constant 
temperature was maintained. The shelter is located $1.5 \mathrm{~m}$ above the ground. The gamma spectra are recorded with a computer add-on board containing a high-voltage supply for the photomultiplier tube, a shaping amplifier and a 1024channel pulse-height analyzer. The energy spectra between 100 and $3000 \mathrm{keV}$ are acquired in 10-minute intervals using a digital spectrum stabilizer. The observed count rates are converted to the dose rate units with a calibration factor obtained by a comparison to a calibrated pressurized ionization chamber. The dose rate values $\left(\mathrm{mGy} \mathrm{h}^{-1}=\mathrm{mJ} \mathrm{kg}^{-1} \mathrm{~h}^{-1}\right)$ are converted to ion production rates (ion pairs $\mathrm{m}^{-3} \mathrm{~s}^{-1}$ ) by assuming an average energy of $34 \mathrm{eV}$ per produced ion pair. The uncertainty in ionization rate caused by the external radiation is $\pm 10 \%$.

2.5 Ion production rate calculated from ion and aerosol particle measurements

The balance equation for the small cluster ion concentration is (Israel, 1970)

$$
\frac{d n_{ \pm}}{d t}=Q-\alpha n_{ \pm} n_{\mp}-n_{ \pm} \int_{d_{p}} \sum_{q=-\infty}^{\infty} \beta_{ \pm}\left(d_{p}, q\right) N\left(d_{p}, q\right) d d_{p}
$$

where $Q$ is the ion production rate, $\mathrm{n}_{ \pm}$is the concentration of positive or negative cluster ions, $\alpha$ is the ion-ion recombination coefficient, $\beta_{ \pm}\left(d_{p}, q\right)$ the cluster ion-aerosol particle attachment coefficient, $q$ is the charge of the aerosol particle and $N\left(d_{p}, q\right)$ the concentration of aerosol particles. The sink of small ions by ion-induced nucleation is not taken into account in this simplified balance equation. In the case of steady state, the derivative in Eq. (2) is equal to zero and thus the ion production rate $Q$ can be obtained. This leads to

$$
Q=\alpha n_{ \pm} n_{\mp}+n_{ \pm} \int_{d_{p}} \sum_{q=-\infty}^{\infty} \beta_{ \pm}\left(d_{p}, q\right) N\left(d_{p}, q\right) d d_{p}
$$

Because the concentrations of cluster ions and aerosol particles are measured and the recombination and attachment coefficients can be calculated, it is possible to estimate $Q$ from measurements independently of direct measurements.

Both the DMPS and the APS measured size distributions of dry particles. Thus, the effect of ambient relative humidity had to be somehow taken into account. In this work, we used a simple parameterization suggested by Zhou (2001)

$G F=(1-R H / 100)^{\gamma(d p)}$.

This parameterization gives the particle growth factor GF (ie. how much the particle diameter is increased), due to absorption of water vapour as a function of relative humidity (RH). The above parameterization was based on measurements conducted in the Arctic Ocean. In this study we used $\gamma(d p)$ values obtained by fitting a first order polynomial to the measurements carried out in Hyytiälä during the BIOFOR (Biogenic Aerosol Formation in the Boreal Forest) campaign (Hämeri et al., 2001) for the size range 10$264 \mathrm{~nm}$. The growth factors of possible different externally mixed (hygroscopicity) modes were weighted by their corresponding fractions. The size dependence of the exponential $\gamma$ was obtained by optimizing a linear function, to obtain

$\gamma=-3.11 \cdot 10^{5} \cdot d p / d p_{0}-0.0847$.

where the non-dimensionalizing factor $d p_{0}$ is $1 \mathrm{~m}$. The growth factors during QUEST 2-campaigns were measured with two independent devices at a constant relative humidity. A Hygroscopic Tandem Differential Mobility analyzer (HTDMA) (e.g. Hämeri et al. (2000)) measured growth factors for monodisperse aerosol samples $(8,10,20$ and $50 \mathrm{~nm}$ in diameter) at $90 \%$ RH. A wet-DMPS was used to measure aerosol growth and the consequent size distribution change at $90 \% \mathrm{RH}$ for particles from 3 to $70 \mathrm{~nm}$ in diameter. The largest contribution to the condensation sink comes from accumulation mode particles, of which we did not have any hygroscopicity measurements. Existing measurements, however, can be used to establish the quality of the parameterization. For $90 \% \mathrm{RH}$, the parameterization gives a growth factor of 1.2-1.3. Based on the HTDMA measurements, the average growth factor for $50 \mathrm{~nm}$ particles was $1.29 \pm 0.11$ for the whole campaign period. At the same time the wetDMPS measurements gave a growth factor of about 1.14 (standard deviation $\sigma=0.18$ ) at $90 \%$ to the nucleation mode particles (average dry diameter about $20 \mathrm{~nm}$ ). During nucleation events the average growth factor and dry particle diameter were about $1.08(\sigma=0.14)$ and $9 \mathrm{~nm}(\sigma=3 \mathrm{~nm})$, respectively. Thus, the parameterization seems to produce reasonable values in the Aitken size range, whereas it overestimates the growth for the nucleation mode particles.

Based on Eq. (3), measured dry size spectra were converted to wet size spectra at ambient relative humidities.

The ion-aerosol attachment coefficients were calculated according to Fuchs attachment theory (Fuchs, 1964) based on measured mobilities and temperatures. The masses of the ions were estimated according to the method given by Tammet (1998), in which the small ion mass is correlated with its mobility by

$K=\left(\frac{1200 u}{m_{\text {ion }}}\right)^{1 / 3}-0.2$

where $K$ is in $\mathrm{cm}^{2} \mathrm{~V}^{-1} \mathrm{~s}^{-1}$, and the mass $m_{\text {ion }}$ is in the range of 30-2100 u. The correlation is based on experimental data by Kilpatric (1971). Next the mean mobility of cluster ions was calculated based on BSMA-measurements. Only negative ions were utilized in our studies since positive ions gave approximately similar results. Finally, Eq. (2) was solved for each individual measured particle size distribution spectrum to obtain the ion production rate $\mathrm{Q}$.

\section{Results}

In this study, we used the period 20 March-11 April or days 79-101 of the year 2003. All data was interpolated to correspond to the time resolution of the BSMA, 


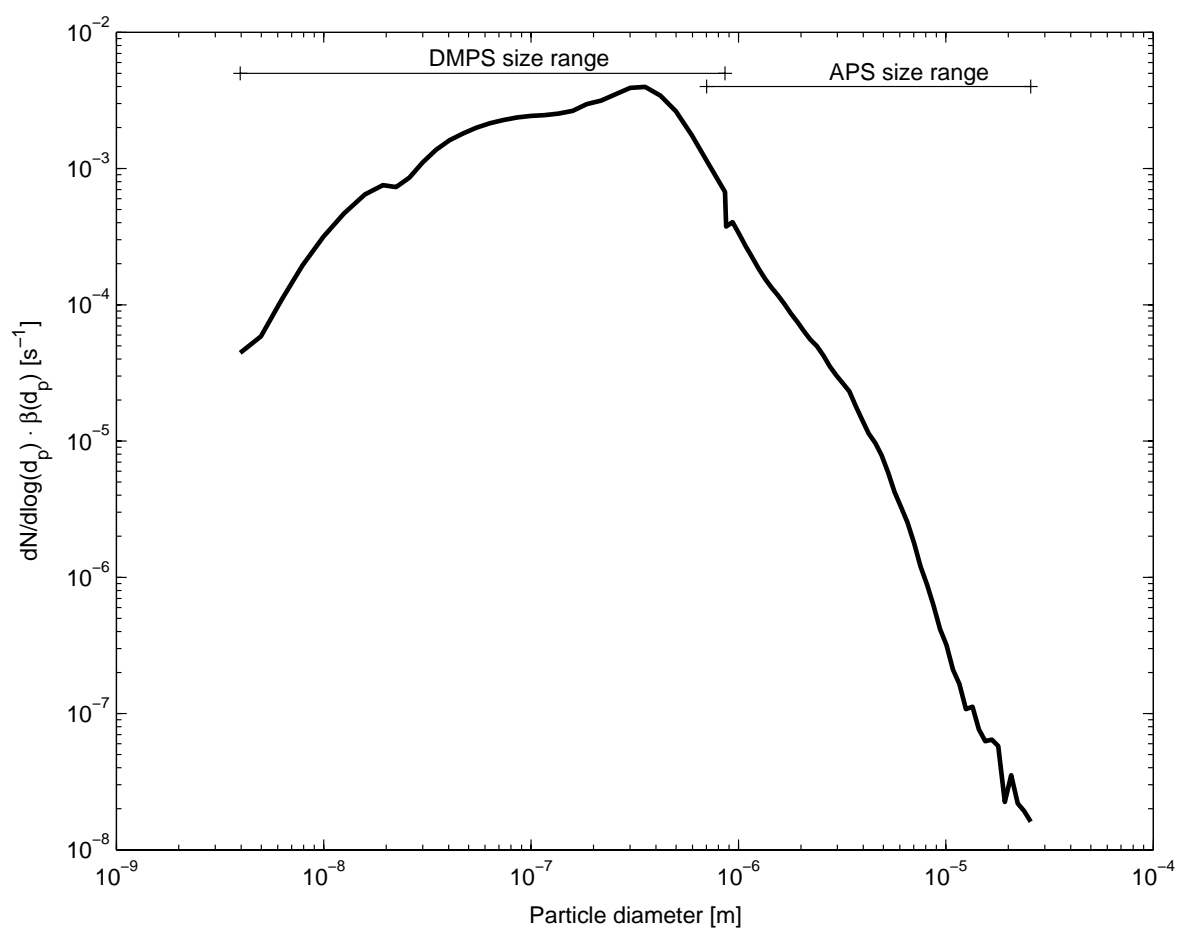

Fig. 2. Average factor $d N / d \log \left(d_{p}\right) \beta\left(d_{p}, q\right)$ (see Eq. 2) for period from 20 March to 13 April 2003. Size ranges of DMPS and APS corresponding to relative humidity $90 \%$ are also shown.

Table 1. Statistical characteristics (mean, $25 \%, 50 \%, 75 \%$ quantiles and standard deviation) of estimated ion production rates, in $\mathrm{cm}^{-3} \mathrm{~s}^{-1}$

\begin{tabular}{ll|lllll|llllll}
\hline & \multicolumn{5}{|c}{ Whole period } & \multicolumn{5}{c}{ Day 84 (March 25) } \\
& & Mean & $25 \%$ & $50 \%$ & $75 \%$ & $\sigma$ & Mean & $25 \%$ & $50 \%$ & $75 \%$ & $\sigma$ \\
\hline \multirow{3}{*}{ Measured } & External & 3.99 & 3.51 & 3.68 & 4.60 & 0.59 & 3.93 & 3.90 & 3.92 & 3.95 & 0.03 \\
& Radon & 0.34 & 0.23 & 0.43 & 0.65 & 0.32 & 0.35 & 0.13 & 0.27 & 0.58 & 0.22 \\
& Sum & 4.47 & 3.74 & 4.11 & 5.25 & - & 4.27 & 4.03 & 4.19 & 4.53 & - \\
& & & & & & & & & & & \\
Calculated & DMPS-range & 1.93 & 1.28 & 2.02 & 2.92 & 0.93 & 1.74 & 1.17 & 1.67 & 2.23 & 0.71 \\
& APS-range & 0.09 & 0.03 & 0.05 & 0.13 & 0.30 & 0.06 & 0.02 & 0.03 & 0.09 & 0.05 \\
& Recombination & 0.64 & 0.42 & 0.69 & 1.04 & 0.39 & 0.99 & 0.76 & 0.89 & 1.15 & 0.34 \\
& Sum & 2.63 & 2.08 & 2.74 & 3.96 & - & 2.79 & 1.94 & 2.86 & 3.47 & - \\
\hline
\end{tabular}

namely 360 seconds. The average ion production rate calculated from DMPS, APS and BSMA-measurements was 2.6 ion pairs $\mathrm{cm}^{-3} \mathrm{~s}^{-1}$ and from external radiation and radon measurements it was 4.5 ion pairs $\mathrm{cm}^{-3} \mathrm{~s}^{-1}$ (Table 1). During the study period the amount of ${ }^{220} \mathrm{Rn}$ progeny and artificial radioactivity in the air was insignificant compared to the amount of ${ }^{222} \mathrm{Rn}$.

In the case of direct measurements, the external radiation was mostly responsible for ion production; the contribution from radon was about $10 \%$, with a maximum value of about $36 \%$ recorded on 26 March, 1999, in Hyytiälä.

In the case of the indirect method, ion sink and thus ion production rate were mainly influenced by the concentration of particles in the size range of 5-500 $\mathrm{nm}$ measured by means of DMPS. The contribution of large particles (measured by APS) was always less than $10 \%$, having an average about $2 \%$. Also the effect of ion-ion recombination was significant.

The ion sink size distribution $\mathrm{dN} / \mathrm{d} \log \left(\mathrm{d}_{p}\right) \cdot \beta_{ \pm}\left(\mathrm{d}_{p}, \mathrm{q}\right)$ is shown in Fig. 2 using an average mobility $1.23 \times 10^{-4} \mathrm{~cm}^{2} \mathrm{~V}^{-1} \mathrm{~s}^{-1}$, temperature $+5^{\circ} \mathrm{C}$ and relative humidity $90 \%$. The DMPS and APS size ranges corresponding to $90 \%$ relative humidity are also shown. It can be seen that the ion sink is dominated by the particle diameter range 30-700 $\mathrm{nm}$.

The ion production rates calculated with the two different methods are shown in Fig. 3. Both measurements showed 


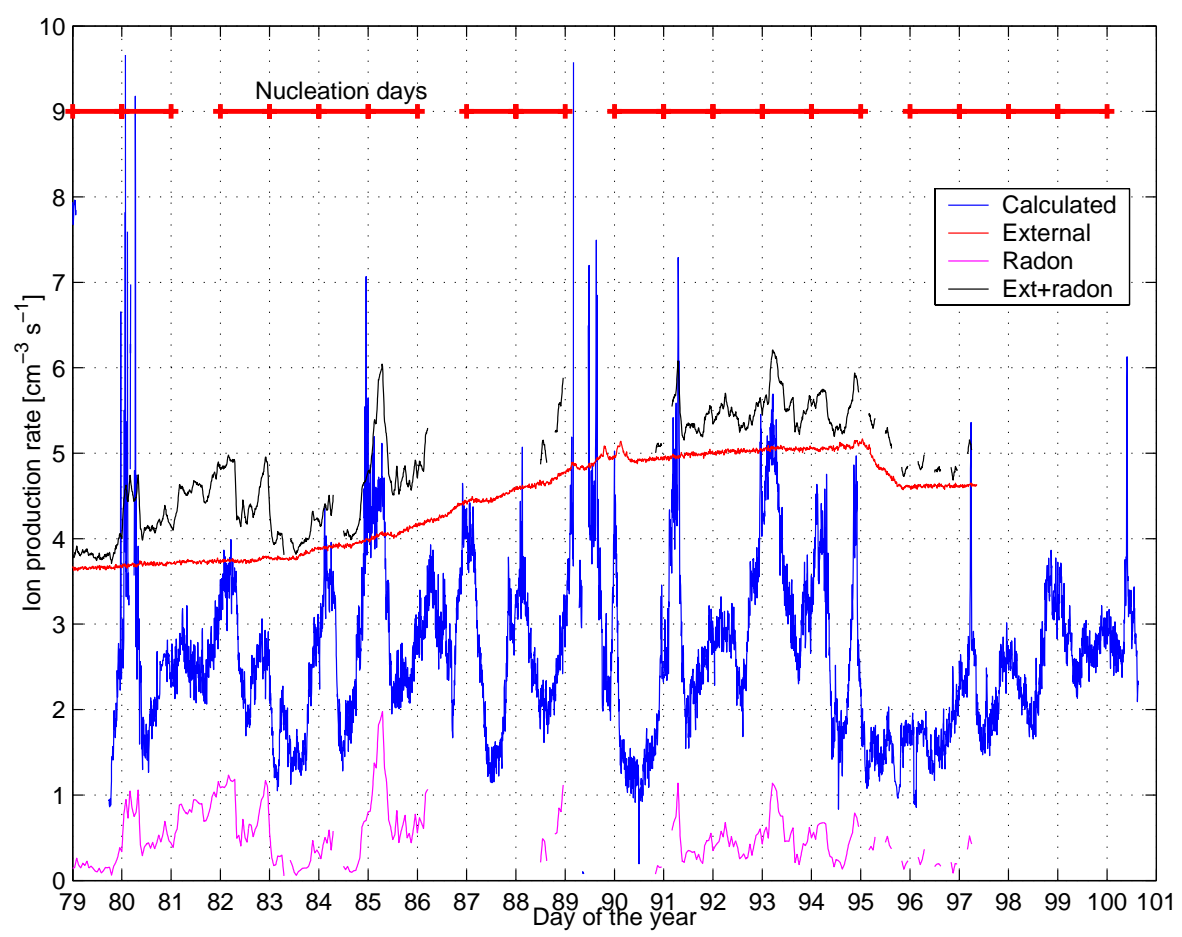

Fig. 3. Ion production rates calculated from external radiation and radon measurements and based on DMPS, BSMA and APS measurements. In addition, days with clear particle formation are shown.

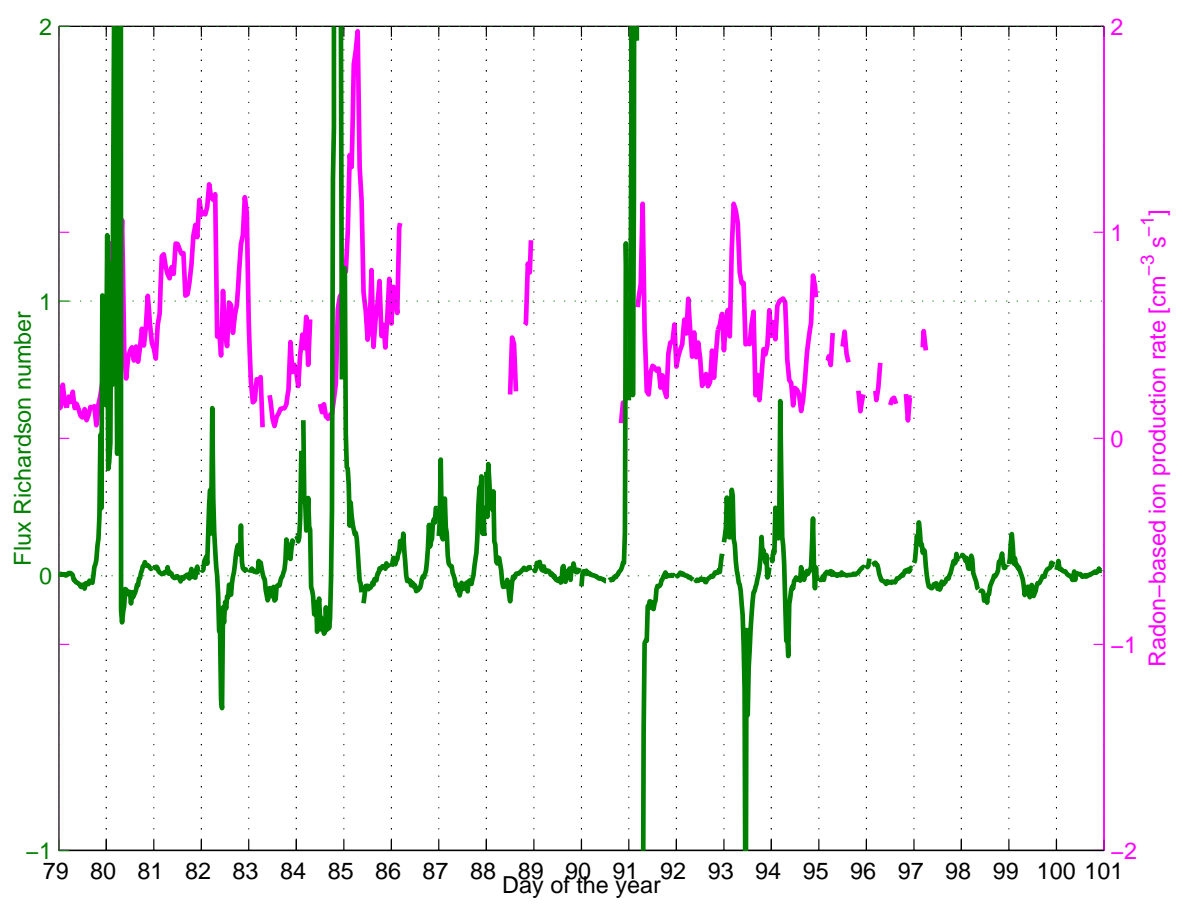

Fig. 4. Radon-based ion production and the stability of the lower boundary layer indicated by the flux Richardson number $R f$ 

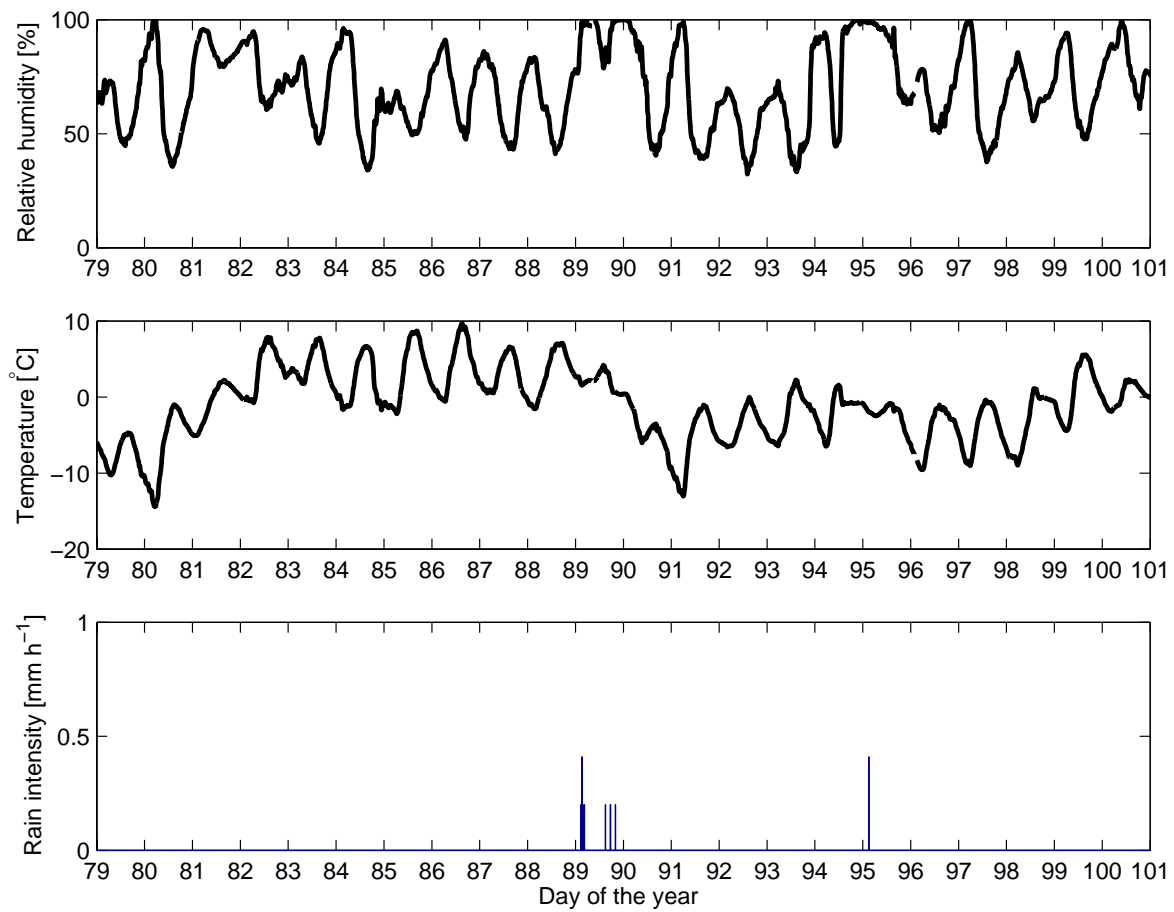

Fig. 5. Relative humidity, air temperature and rain intensity during the QUEST 2-campaign.

the highest ion production rates in the middle of the measurement period. However, the ion production rates obtained from external radiation and radon measurements have much less variability than the rates calculated from ion and particle measurements. One similar feature for both methods is that the ion production rate is highest during nighttime. This is likely to be due to radon accumulation on the surface layer during the stable nighttime conditions. One good measure of boundary layer stability is the so-called Flux Richardson number $R f$ (Seinfeld and Pandis, 1998) which is based on heat and momentum fluxes measured by eddy covariance technique. In Fig. $4 R f$ is shown together with the radonbased ion production rate. During the night $R f$ is often positive representing stable conditions. The curves representing $R f$ and radon-based ion production have certain key features: the ion production rate is peaking after $R f$ because radon is accumulating during the night and the concentration reaches its maximum in the early morning. During day 81 there is only very little mixing, so radon is accumulating for a longer period than one night.

To check the effect of the growth factor parameterization to the results, the growth factors were varied by $\pm 10 \%$ compared to Eq. (3). The resulting ion production rates were 2.4 ion pairs $\mathrm{cm}^{-3} \mathrm{~s}^{-1}$ (for $-10 \%$ ) and 2.9 ion pairs $\mathrm{cm}^{-3} \mathrm{~s}^{-1}$ (for $+10 \%$ ), so the hygroscopic growth factor has indeed a significant effect on the ion sink and therefore on the calculated ion production rate. In addition the diurnal cycle of RH amplifies the effect. However, it can not explain the systematic differences between the ion production rates obtained by these two methods. Two other tests were made to check the assumptions used in the calculations. One average cluster ion size instead of six cluster ion size intervals were used in the calculations. The effect was, on average, less than one percent compared to the case where the ion loss rate was calculated separately for all the six size classes and then summed up.

Another approximation was made regarding hygroscopic growth. We used one average growth factor for all particles of a certain size. However, in reality, there is normally several external hygroscopic growth modes present in the atmosphere (Hämeri et al., 2001). Because the ion loss is proportional to the diameter of the particle, using an average growth factor may lead to errors. However, the the effect of hygroscopic mode separation was found to be less than $5 \%$ compared to one average growth factor.

In case of high relative humidity, there may be fog formation causing an additional sink to the ions. Unfortunately, we did not have fog measurements during the QUEST 2campaign. However, at least during days 81, 89 and 95 the relative humidity stayed high all day (Fig. 5) which indicates fog formation and thus an increased ion loss rate. The same applies for rain episodes: it is observed that rain droplets are charged, consequently the scavenging of ions onto rain droplets may reduce the concentration of ions. However, there was practically no rain during the period; only during days 89 and 95 there were some precipitation. Based on earlier data from the BIOFOR III-campaign (Hõrak et al., 2003), it seems that rain normally does not significantly 

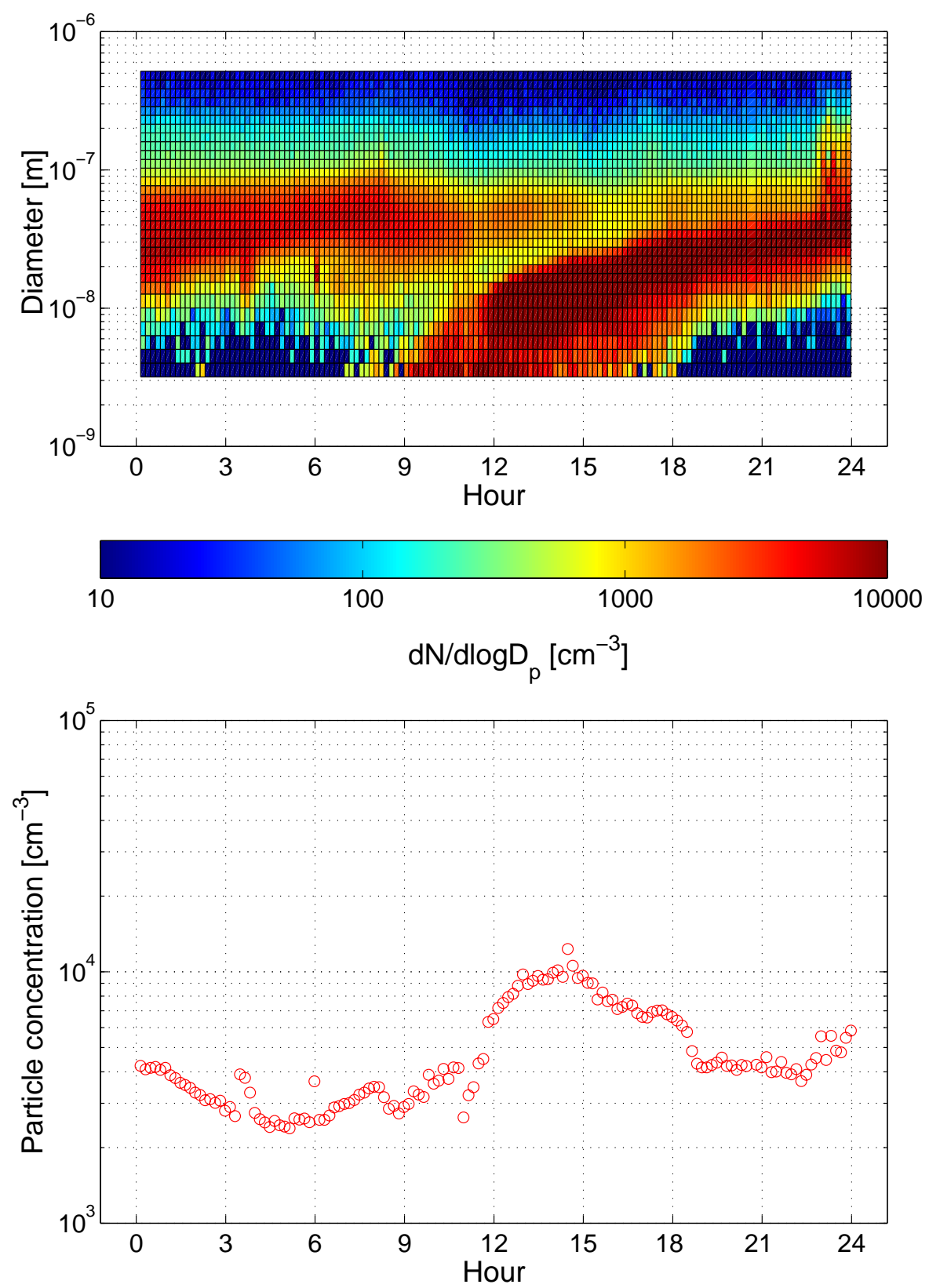

Fig. 6. Particle size spectrum measured by DMPS in 25 March 2003 (upper panel) and and the particle concentrations with diameter from 3 to $500 \mathrm{~nm}$ as a function of time of the day (lower panel).

change the concentration of small ions. Lower concentrations were observed only when the RH was over $98 \%$. During the whole period used in the present study, there was snow cover at Hyytiälä measurement station.

During the nucleation bursts, there is a possible additional sink of small ions by ion-induced nucleation. Nanometer sized particles are sometimes observed to be slightly overcharged (Laakso et al., 2004), which indicates an effect of ions on the nucleation process. Another, more probable ion sink during the nucleation burst is caused by the particles in the diameter range of $1.5-3 \mathrm{~nm}$, which are not measured by common aerosol instruments. If we for example assume a concentration of $1.5-3 \mathrm{~nm}$ particles of $30000 \mathrm{~cm}^{-3}$, a value that is based on model studies (Laakso et al., 2004), and a concentration of small ions of $1000 \mathrm{~cm}^{-3}$, the additional ion sink is roughly 1 ion pair $\mathrm{cm}^{-3} \mathrm{~s}^{-1}$ during the nucleation bursts.

The concentration of particles below the detection limit of the dry DMPS $(3 \mathrm{~nm})$ can be estimated from wet-DMPS results since the particles can grow to detectable size during 


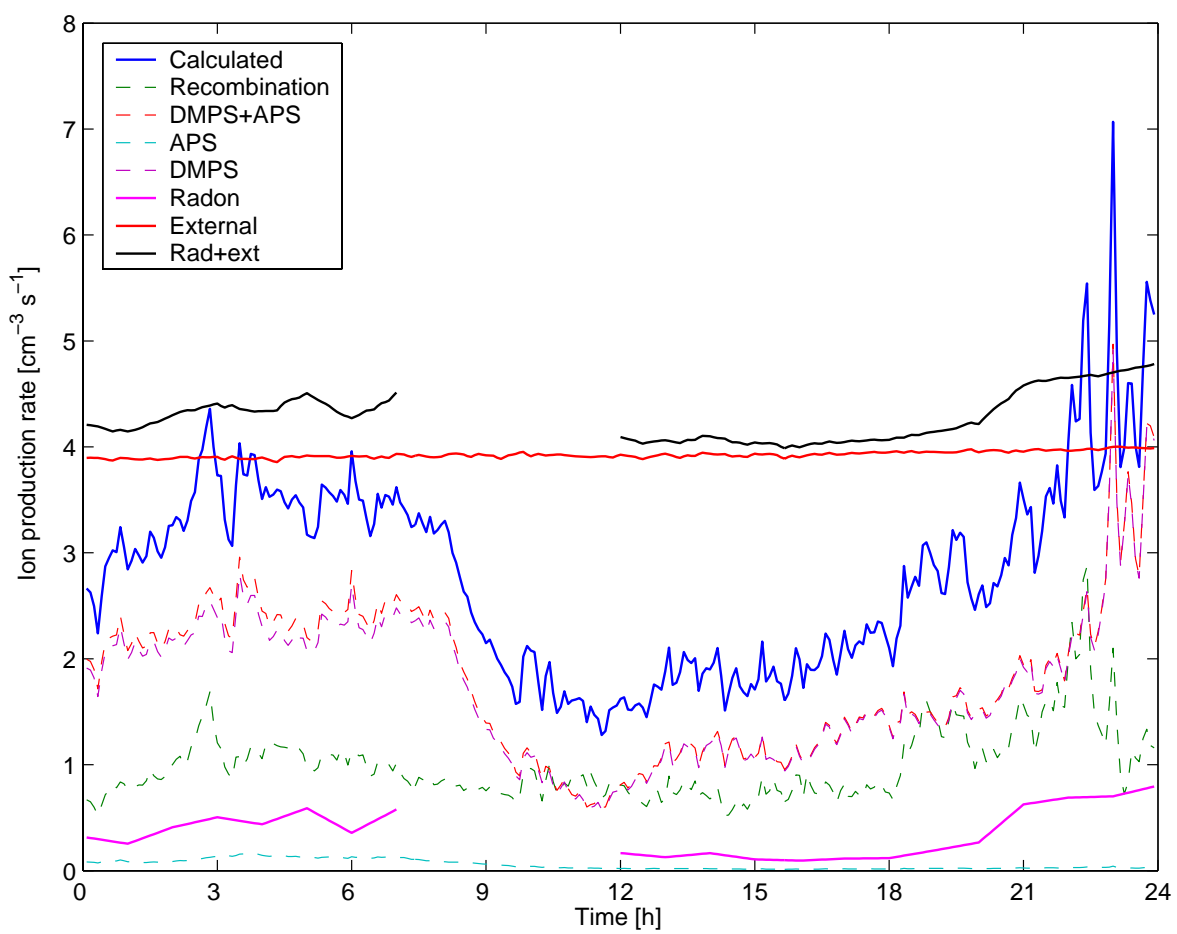

Fig. 7. Ion production rate during on 25 March 2003 (day 84). Calculated mean of the sum of recombination and APS- and DMPS-size ranges, All particles is the combination of DMPS- and APS-size ranges.

humidification. The concentration of $2.5-3.0 \mathrm{~nm}$ particles has been estimated assuming that the growth factor of the fine particles is about 1.2. The average concentration is approximately $200 \mathrm{~cm}^{-3}$ over all measurement days and about $700 \mathrm{~cm}^{-3}$ during nucleation events. The maximum observed $2.5-3 \mathrm{~nm}$ particle concentration is around $8000 \mathrm{~cm}^{-3}$ which indeed has a significant effect on the ion concentration during the nucleation events.

One of the most interesting features of these kind of simulations is that they offer us a method to study the existence of so called thermodynamically stable clusters (TSCs) (Kulmala et al., 2000b). TSCs cannot be observed directly by standard aerosol size distribution measurements because of their small size (of order $1 \mathrm{~nm}$ ). If the background particle concentration is so high that it hinders particle growth to observable sizes, there can still be enough particles to cause an additional ion sink which can be seen from the difference of calculated and radon and external radiation based measurements. It has been previously found that TSC's may form nearly every day, but they can only be observed after growth to sufficiently large sizes before they are scavenged. If we, for example, compare sunny (=there is sulphuric acid formation) and cloudy days with relatively high background concentrations, we may see a difference caused by the TSC's. This particle formation pathway, however, may be in interplay with ion-accelerated cluster formation (Laakso et al., 2004), and the relative importance of the mechanisms are yet unknown.
There are also some more causes of uncertainties. The orography of the measurement locations may have an effect on the systematic differences between these two methods. This is because the concentrations of radon and ions were measured a few tens of meters apart and at different heights (of about 6 and $2 \mathrm{~m}$, respectively). The forest canopy may also provide an additional sink for the ions, which was not taken into account in this study. The applied model of the ionization process has also some degree of approximation. The measured dose rate and radon concentration data were converted to ion production rates by assuming that all the energy goes to ionization and that it takes $34 \mathrm{eV}$ to produce one ion pair in air. In reality a part of the energy is, however, consumed to other processes. After the alpha particle emission the recoiling daughter nucleus can also cause intense ionization but within a very short distance.

One other uncertainty is related to the lack of knowledge on the ion-ion recombination process in the real atmosphere. The recombination is a three-body process (Bates, 1985), and depends on the mobility and energy of ions. The mobility depends on ion-cluster formation (initial species, free electron and positively charged kernel of "air molecule" after about 1 microsecond form ion clusters). It is rational to assume that the recombination rate of ion-clusters just after the ionization act in the vicinity of "ionization-track", is higher than after its dispersion. Therefore the recombination rate is dependent on the type of ionizing radiation (alpha, beta, gamma); it is highest in the case of alpha-radiation (short tracks) and lowest in 
the case of gamma-radiation (uniform ionization through the volume). In this study we used the value $1.6 \times 10^{-6} \mathrm{~cm}^{3} \mathrm{~s}^{-1}$ for the recombination coefficient, a value often cited in the textbooks of atmospheric electricity (Israel, 1970).

In addition to the studied period, one particular day, 25 March 2003 (day 84) was chosen to be investigated in more detail. This day was chosen because it was one of the clearest particle formation days during the campaign. The number distribution evolution as well as the total number concentration evolution of the day are shown in Fig. 6. During this day the ion production rates estimated by the two methods displayed nearly equal values during nighttime, but considerable difference during daytime.

The contributions of different model calculations and radiation measurements on 25 March 2003 are shown in Fig. 7 and Table 1. Recombination is quite steady during the day, whereas some other sinks are underestimated. The expected increment of the ion production rate of about 1 ion pairs $\mathrm{cm}^{-3} \mathrm{~s}^{-1}$ caused by an additional hypothetical sink of small ions, followed the generation of $1.5-3 \mathrm{~nm}$ particles of about $30000 \mathrm{~cm}^{-3}$ around noon, is enough to explain the discrepancy between the results of two methods in this case.

\section{Conclusions}

In the current study the ion production rates in a boreal forest were studied based on two different methods: 1) external radiation and radon concentration, 2) ion and particle concentrations. The average ion production rate calculated from DMPS, APS and BSMA-measurements was 2.6 ion pairs $\mathrm{cm}^{-3} \mathrm{~s}^{-1}$ and based on external radiation and radon measurements 4.5 ion pairs $\mathrm{cm}^{-3} \mathrm{~s}^{-1}$. The method, based on ion and particle measurements, underestimates the ion production rates especially during the day. There are two main reasons for this underestimation: the particle measurements start only from $3 \mathrm{~nm}$, hence the sink of ions during the nucleation events is underestimated. It is also possible that the contribution of ions on the nucleation process leads to an underestimation of the sink. Also other, orographical and methodological effects may lead to some systematic differences between the methods.

Despite some differences, both method gave reasonable estimates on ion production rate. The results will be utilized in our future studies.

Edited by: K. Hämeri

\section{References}

Aalto, P., Hämeri, K., Becker, E., Weber, R., Salm, J., Mäkelä, J. M., Hoell, C., O’Dowd, C. D., Karlsson, H., Hansson, H.C., Väkevä, M., Koponen, I. K., Buzorius, G., and Kulmala, M.: Physical characterization of aerosol particles during nucleation events, Tellus, 53B, 344-358, 2001.

Bates, D.: Ion-ion recombination in an ambient gas, Adv. At. Mol. Phys., 20, 1-40, 1985.

Chalmers, J.: Atmospheric Electricity, Pergamon Press, Oxford, London, 1967.

Dhanorkar, S. and Kamra, A.: Diurnal variation of ionization rate close to ground., J. Geophys. Res., 99, 18 523-18 526, 1994.

Fuchs, N. A.: The mechanics of Aerosol, Pergamon, New York, 1964.

Hõrrak, U., Aalto, P., Salm, J., and Kulmala, M.: Characterization of air ions during nucleation events in boreal forest air, in Report Series in Aerosol Science 59, pp. 196-201, 2003.

Hämeri, K., Väkevä, M., Hansson, H.-C., and Laaksonen, A.: Hygroscopic growth of ultrafine ammonium sulphate aerosol measured using an ultrafine tandem differential mobility analyser., J. Geophys. Res., 105, 22 231-22 242, 2000.

Hämeri, K., Väkevä, M., Aalto, P. P., Kulmala, M., Swietlicki, E., Zhou, J., Seidl, W., Becker, E., and O'Dowd, C. D.: Hygroscopic and $\mathrm{CCN}$ properties of aerosol particles in boreal forests, Tellus, 53B, 359-379, 2001.

Hensen, A. and van der Hage, J. C. H.: Parametrization of cosmic radiation at sea level, J. Geophys. Res., 99, 10 693-10 695, 1994.

Hoppel, W., Anderson, R., and Willett, J.: The Earths Electrical Environment, chap. Atmospheric electric, pp. 149-165, National Academy Press, Washington, D.C., 1986.

Israel, H.: Atmospheric electricity, Vol 1., Israel Program for Scientific Translations, Jerusalem, 1970.

Israel, H.: Atmospheric electricity, Vol. 2, Israel Program for Scientific Translations, Jerusalem, 1973.

Jokinen, V. and Mäkelä, J. M.: Closed loop arrangement with critical orifice for DMA sheath/excess flow system, J. Aerosol Sci., 28, 643-648, 1997.

Joutsensaari, J. , Vaattovaara, P. , Vesterinen, M. , Hämeri, K., and Laaksonen, A.: A novel tandem differential mobility analyzer with organic vapor treatment of aerosol particles, Atmos. Chem. Phys., 1, 51-60, 2001,

SRef-ID: 1680-7324/acp/2001-1-51.

Kataoka, T., Yunoki, E., Shimizu, M., Mori, T., Tsukamoto, O., Ohhashi, Y., Sahashi, K., Maitani, T., Miyashita, K., Fujikawa, Y., and Kudo, A.: Diurnal variation in radon concentration and mixing-layer depths, Boundary-Layer Meteorology, 89, 225250, 1998.

Kilpatric, W.: An experimental mass-mobility relation for ions in air at atmospheric pressure, in Proc. Annu.Conf. Mass.Spectrosc. 19th., pp. 320-325, 1971.

Kulmala, M., Korhonen, P., Laakso, L., and Pirjola, L.: Nucleation in boreal forest boundary layer, Environ. Chem. Phys., 22, 4653, 2000a.

Kulmala, M., Pirjola, L., and Mäkelä, J. M.: Stable sulphate clusters as a source of new atmospheric particles, Nature, 404, 66-69, $2000 b$.

Kulmala, M., Hämeri, K., Aalto, P., Mäkelä, J., Pirjola, L., Nilsson, E. D., Buzorius, G., Rannik, Ü., Dal Maso, M., Seidl, W., Hoffmann, T., Jansson, R., Hansson, H.-C., O`Dowd, C., and 
Viisanen, Y.: Overview of the international project on biogenic aerosol formation in the boreal forest (BIOFOR), Tellus, 53B, 324-343, 2001.

Kulmala, M., Vehkamäki, H., Petäjä, T., Dal Maso, M., Lauri, A., Kerminen, V.-M., Birmili, W., and McMurry, P.: Formation and growth rates of ultrafine atmospheric particles: a review of observations, J. Aerosol Sci., 35, 143-176, 2004.

Laakso, L., Anttila, T., Lehtinen, K., Aalto, P., Kulmala, M., Hõrrak, U., Paatero, J., Hanke, M., and Arnold, F.: Kinetic nucleation and ions in boreal forest particle formation events, Atmos. Chem. Phys. Discuss., 4, 3911-3945, 2004,

\section{SRef-ID: 1680-7375/acpd/2004-4-3911.}

Larsen, R.: Global decrease of beryllium-7 in surface air, J. Environ. Radioact., 18, 85-87, 1993.

Liu, S., McAfee, J., and Cicerone, R.: Radon-222 and Tropospheric Vertical Transport, J. Geophys. Res., 89, 7291-7297, 1984.

Mochizuki, S., Namiki, Y., Kato, T., Masuda, S., and Sekikawa, T.: Electrical Processes in Atmospheres, chap. A technique for cont, pp. 204 -210, Dr. Dietrich Steinkopff Verlag, Darmstadt, Germany, 1977.

Mohnen, V.: Electrical Processes in Atmospheres, chap. Formation, nature an, pp. 1-17, Dr. Dietrich Steinkopff Verlag, Darmstadt, Germany, 1977.

Paatero, J., Hatakka, J., and Viisanen, Y.: Concurrent Measurements of Airborne Radon-222, Lead-210 and Beryllium-7 at the Pallas-Sodankylä GAW Station, Northern Finland, Tech. rep., Finnish Meteorological Institute, 1998.

Peters, T. M. and Leith, D.: Concentration measurement and counting efficiency of the aerodynamic particle sizer 3321, J. Aerosol. Sci., 34, 627-634, 2003.
Porstendörfer, J.: Properties and behaviour of radon and thoron and their decay products in the air, J. Aerosol Sci., 25, 219-263, 1994.

Rosen, J., Hofmann, D., and Gringel, W.: Measurements of ion mobility to $30 \mathrm{~km}$, J. Geophys. Res., 90, 5876-5884, 1985.

Seinfeld, J. H. and Pandis, S. N.: Atmospheric Chemistry and Physics: From Air Pollution to Climate Change, Wiley, New York, 1998.

Tammet, H.: Size and mobility of nanometer particles, clusters and ions, J. Aerosol Sci., 26, 459-475, 1995.

Tammet, H.: Reduction of air ion mobility to standard conditions, J. Geophys. Res.-Atmos., 103, 13 933-13 937, 1998.

Vesala, T., Haataja, J., Aalto, P., Altimir, N., Buzorius, G., Garam, E., Hämeri, K., Ilvesniemi, H., Jokinen, V., Keronen, P., Lahti, T., Markkanen, T., Mäkelä, J., Nikinmaa, E., Palmroth, S., and Palv: Long-term field measurements of atmosphere-surface interactions in boreal forest combining forest ecology, micrometeorology, aerosol physics and atmospheric chemistry, Trends in Heat, Mass \& Momentum Transfer, 4, 17-35, 1998.

Wilkening, M.: Characteristics of atmospheric ions in contrasting environments, J. Geophys. Res., 90, 5933-5935, 1985.

Winklmayr, W., Reischl, G.P.and Lindner, A., and Berner, A.: A new electromobility spectrometer for the measurement of aerosol size distributions in the size range from 1 to $1000 \mathrm{~nm}$, J. Aerosol Sci., 22, 289-296, 1991.

Yu, F. and Turco, R. P.: Ultrafine aerosol formation via ionmediated nucleation, Geophys. Res. Lett., 27, 883-886, 2000.

Zhou, J.: Hygroscopic properties of atmospheric aerosol particles in various environments, Ph.D. thesis, University of Lund, Division of Nuclear Physics, Sweden, 2001. 